\title{
The Concrete Reinforcing Value of Recycled Steel Bars in Uganda
}

\author{
Senfuka C., Kirabira J.B., Byauhanga J.K.
}

\begin{abstract}
The energy absorbing capacity of the reinforcement bars in concrete only occurs after the yield point. If the yield point of steel is too high, stresses in the concrete reach failure level before the yield point of the steel, allowing the formation of large shear and bond stresses at time of yield and ultimate brittle collapse. High yield is equally associated with reduced yield platform and energy absorption. Steel reinforcement bars in Uganda, mainly cold twisted, are often of high yield even though they amply meet the standard ductility requirements. This has largely been attributed to their recycled origin. This research investigates the relationship between the elevated yield values and the residual element content which in turn is a direct result of steel recycling.
\end{abstract}

Keywords: steel reinforcement, residual elements, yield point, ductility, recycled steel.

\section{INTRODUCTION}

Steel exhibits linear elasticity within the elastic limit until yielding occurs. Beyond this point and prior to ultimate failure, stress is no longer proportional to strain. However, a considerable amount of energy is absorbed within the yield plateau and in the strain hardening portion prior to failure. The prevalence of the zone between the yield point and the maximum stress point is a measure of ductility.

Steel is widely used in the building construction practice to impart ductility and tensile strength to concrete, being inherently brittle.

Ductility in concrete beams means the ability of the member to survive large deformations and its capacity to absorb energy in the event of failure. This failure would be initiated by gradual yielding of the steel while concrete strains are still relatively low. Thus large deflections would be attained before the final collapse occurs so that the members bend and deform substantially but remain intact, providing ample and probably visible warning to occupants.

Most of the steel produced in Uganda is quite ductile, showing the usual yield platform, a strain hardening portion, a strain softening zone prior to failure. This is however almost always compounded with rather high yield stress $\left(\sigma_{\mathrm{y}}\right)$ and an equally high ultimate stress $\left(\sigma_{\mathrm{u}}\right)$, often believed to mean high quality since it surpasses the minimum required standards.

Without doubt, the strength of steel is the main factor that determines the force-bearing capacity of the reinforced concrete structure. This would mean the higher the strength of reinforcing bars, the greater the load bearing capacity of the concrete structure and therefore the more effective it is. The economic efficiency of steel is actually gauged by its strength to price ratio (MPa.kg / USD) (Xu Youlin, 2010).

Fig. 1 shows the stress-strain diagrams of several steels with different yield-stress levels. It can be appreciated that the higher the $\sigma_{y}$, the smaller the yield plateau. The strain hardening zone is similarly reduced indicating less energy absorption in the overall plastic zone.

A generous yield plateau shows a long period of energy absorption of the steel prior to the commencement of the stain hardening zone. Deformation in the strain-hardening zone however, is not as desirable because the steel yield stress $\sigma_{\mathrm{y}}$ keeps elevating in the reinforced concrete beam section and may grow to even exceed the predetermined design yield level (Bull D. et al 2003).

The fact that these bars are basically for reinforcing concrete makes the yield point an issue for serious consideration. Ideally the only desirable mode of failure is a ductile one and can be initiated by gradual yielding of the steel while concrete strains are still relatively low; attaining large deflection before final structural collapse occurs. A high yield-stress introduces high concentration of shear and bond stresses, impeding flexibility which would have been a timely energy damper since energy absorption, only initiated after yield, will have been postponed, enabling brittle failure modes to prevail (Paulay T, et al, 1992). 


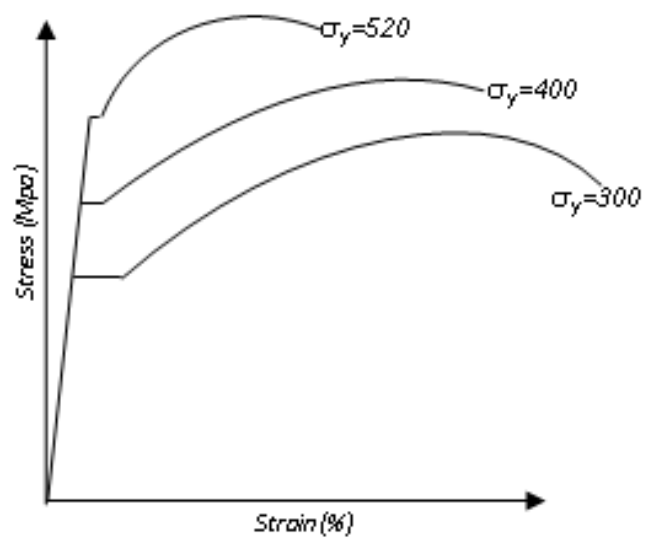

Fig.1: Typiglst tress-strain curver tar reinfarcements teel (Pauley et al, 1992)

The Ugandan building industry, in its most active mode ever, is highly dependent on the steel industry. Unlike in the developed world, the building construction is still heavily dependent on cold twisted (CTD) rather than the globally popular thermal mechanically treated (TMT) or micro-alloyed reinforcement bars even though many of the steel industries in the country have increased the percentage of TMT at the expense of the CTD reinforcement bars.

These bars have an elevated residual element content which affects their yield and ultimate stress values.

This paper attempts to highlight the connection between high yield strength values of the Ugandan reinforcement bars and their exclusively recycled origin together with the need and means of controlling the residual element content which characterizes them.

\section{METHODS}

$300 \mathrm{~mm}$ lengths of $20 \mathrm{~mm}, 16 \mathrm{~mm}, 12 \mathrm{~mm}$ and $10 \mathrm{~mm}$ square section twisted bars were cut from each $6 \mathrm{~m}$ length of 18 reinforcement bars selected from diverse steel bar outlets in the country.

Their ultimate and yield strengths were tested on unmachined samples using MFL SYSTEM hydraulic universal tensile testing machine in accordance to the EAS 412-1:2005 (ISO 6892). Three samples for tensile testing were cut one from each end and one from the middle of the $6 \mathrm{~m}$ steel bars. The yield strength $\sigma_{\mathrm{u}}$ and ultimate strength $\square_{\mathrm{y}}$ were calculated with the initial cross-section area. The composition of samples from each of the bars was determined through spark emission spectrometry using SPECTROL AB apparatus and five bars with the highest yield stresses were analysed.

\section{RESULTS}

Table 1 shows the mechanical properties of the five samples. The values of the yield stress are quite high for grade RB 460 according to EAS 412-1:2005, TS1 returning the smallest at 520Mpa. The corresponding values for tensile stress are similarly elevated. The calculated values of $\sigma_{\mathrm{u}} / \sigma_{\mathrm{y}}$ range between 1.06 and 1.13 , indicating a substantial strain hardening range and apart from TS1 which returned $11 \%$ elongation, the rest of the samples are impressively ductile, ranging between 14 and $21 \%$.

Table 1: Mechanical Properties

\begin{tabular}{ccccc}
\hline Sample & $\sigma_{u}$ & $\sigma_{y}$ & $\sigma_{u} / \sigma_{y}$ & $\delta \%$ \\
\hline TS1 & 573 & 520 & 1.11 & 11 \\
TS2 & 613 & 580 & 1.06 & 16 \\
TS3 & 653 & 584 & 1.12 & 18 \\
TS4 & 648 & 574 & 1.13 & 21 \\
TS6 & 645 & 587 & 1.10 & 14 \\
\hline
\end{tabular}

Table 2 similarly shows the composition of the five samples. Their carbon content, being on the lower range, is between 0.16 and 0.22 . The phophorous and sulphur levels are appreciably low, being between 0.020 and 0.31 . This is in addition to the low manganese levels at $0.46 \leq \mathrm{Mn} \% \leq 0.60$ compared to the allowable $1.6 \%$. 
Table 2: Chemical Composition \%wt

\begin{tabular}{|c|c|c|c|c|c|}
\hline & TS1:16mm & TS2:16mm & TS3:10mm & TS4:10mm & TS6:20mm \\
\hline $\mathrm{C}$ & 0.16 & 0.17 & 0.19 & 0.22 & 0.22 \\
\hline $\mathrm{Si}$ & 0.20 & 0.17 & 0.2 & 0.17 & 0.27 \\
\hline Mn & 0.56 & 0.54 & 0.46 & 0.49 & 0.60 \\
\hline $\mathrm{P}$ & 0.031 & 0.031 & 0.023 & 0.020 & 0.027 \\
\hline S & 0.042 & 0.037 & 0.033 & 0.03 & 0.035 \\
\hline $\mathrm{Cr}$ & 0.11 & 0.1 & 0.09 & 0.07 & 0.12 \\
\hline Mo & 0.01 & 0.009 & 0.010 & 0.009 & 0.008 \\
\hline $\mathrm{Ni}$ & 0.15 & 0.13 & 0.12 & 0.11 & 0.12 \\
\hline $\mathrm{Al}$ & 0.04 & 0.02 & 0.012 & 0.016 & 0.002 \\
\hline $\mathrm{Cu}$ & 0.20 & 0.16 & 0.16 & 0.20 & 0.23 \\
\hline As & 0.015 & 0.0132 & 0.028 & 0.0165 & 0.0175 \\
\hline $\mathrm{Sn}$ & 0.031 & 0.054 & 0.048 & 0.030 & 0.051 \\
\hline $\mathrm{V}$ & 0.002 & 0.003 & 0.001 & 0.003 & 0.001 \\
\hline $\mathrm{Nb}$ & 0.003 & 0.001 & 0.001 & 0.001 & 0.01 \\
\hline B & 0.0016 & 0.0021 & 0.0021 & 0.0013 & 0.0024 \\
\hline $\mathrm{Co}$ & 0.001 & 0.006 & 0.005 & 0.003 & 0.004 \\
\hline
\end{tabular}

\section{DISCUSSION}

Comparing the values in Table1 with the standard requirements of the EAS 412-2:2005 (ISO 6892), it is evident that the yield stresses of the steel bars are quite high. It is often believed that strength values are better the higher they are. This is not true and is in fact self defeating in a way.

The purpose of reinforcing concrete with steel bars is to impose a degree of ductility and tensile strength not attainable with concrete alone. Ductility depicts the ability of a member to survive large deformations; absorbing energy in the process by hysteritic behavior. When steel bars are cast together with concrete to form reinforced-concrete, it is understood that at the time of plastic deformation, the concrete-steel compound structure should be able to deflect together. This actually means that the yield stress of the steel bars which will mainly be experiencing tensile and compressive stresses when the beam is bending must occur at that crucial moment when deformation commences.

Within the yield plateau, a substantial amount of energy is absorbed without further increase in stress, allowing ample warning of the impending structural failure. This is extremely desirable especially as in many cases, this yield point elongation is visually noticeable and is the actual opposite of fragile failure being prevented by the concrete reinforcement in the first place.

In general, the forces that could be developed in a structure during the process of failure decrease with increasing ductility owing to energy absorption (Xu Youlin , 2010). The energy absorption capacity of the fracture is ultimately the real indicator of the ductility inducing effectiveness of steel bars.

Noteworthy too, is that the strain hardening zone that follows the yield-platform as stress increases (Fig. 1) tends to render the reinforcing bars stiffer by increasing yield stress by up to $40 \%$. Ductility reduces simultaneously (Tian Gao et al, 2010).

Basically all tramp elements contribute to an increase in strength and the associated ductility loss. These effects are more pronounced for low carbon steels than for medium and high carbon steel grades (Janke D.et al, 2000).

The difficulty in controlling the tramp element content of steel in the induction furnace process in Uganda, therefore, gives rise to the production of steel of relatively high yield and tensile stresses even though research has shown that the values of tensile to yield stresses are averagely acceptable (Senfuka C. et al, 2012). The addition of atoms of elements that occupy interstitial or substitutional positions in parent iron (steel) lattice increases the strength of parent material by solid solution strengthening. Several of these elements are frequently present in recycled steel and are additive in their effect, increasing the yield point the more the quantities of the elements are present since the shear-stress $\Delta \tau$ required to move dislocations in iron is proportional to the halfroot of the solute (tramp) element concentration as in equation 1 (Meyers et al,2009).

$$
\Delta \tau=G b \epsilon^{3 / 2} \sqrt{c} \text {. }
$$

where $c$ is the tramp element concentration, $\epsilon$ is strain on the material caused by the solute, $G$ is the shear modulus and $b$ the Burgers vector.

The presence of these solute atoms actually imparts compressive or tensile stresses to the lattice, depending on solute atom size. These stresses caused by the strain $\epsilon$ in eq. 1, tend to interfere with nearby dislocations, causing the solute atoms to act as potential barriers to dislocation propagation and their possible 
multiplication and introducing point defects and more grains to pin dislocations. In this way, the solute atoms cause lattice distortions that impede dislocation motion, increasing the yield stress through the increase in shear stress $(\Delta \tau)$ required to initiate plastic deformation of the material (Callister W., 2007).

The non-spherical distortions, known to be caused by most interstitial atoms, have a strong strengthening effect per unit concentration amounting about three times their shear modulus. Conversely, spherical distortion caused by substitutional solute atoms has a relatively smaller strengthening effect being of the order of a tenth of their shear modulus. The strengthening achieved by substitutional solute atoms is, in general, greater the larger the difference in atomic size of the solute from that of iron $(\mathrm{Fe})$ subject to the HumeRothery size effect (Satish V. et al, 2009).

Thus the presence of manganese $(\mathrm{Mn})$, silicate $(\mathrm{Si})$, vanadium $(\mathrm{V})$, niobium $(\mathrm{Nb})$, nickel, molybdenum and a host of other substitutional elements in the steels in this study (Table 1), while increasing the strength of the steel, has had a smaller total effect than that of interstitial elements like boron present in smaller percentages and numbers.

Additionally, the hardenabilty of steel, for example, resulting in the thermal mechanical elevation of the yield point, is known to be increased by the presence of small dissolved amounts of boron in steel in the range of 0.001 to 0.003 .

This is caused by the precipitation of iron boron carbide, $\mathrm{Fe}_{23}(\mathrm{C}, \mathrm{B})_{6}$, at the austenite boundaries during cooling from the fully austenised condition either during billet solidification on casting or during the rolling process, retarding the transformation of austenite to ferrite by impeding the nucleation of ferrite and other soft structures. The effect of boron is higher the lower the carbon content (Murali F. D. et al., 2011). The boron content in this case is in the range 0.0013 to 0.0024 (13ppm to 24ppm). The carbon content is well in the lower range $(0.16 \leq \% \leq 0.22)$.

On the other hand tin (Sn), originating from the tin coating on steel packaging, although not effective in small quantities like $0.03 \%$, actually increases the yield stress of steel by up to $20 \%$ when increased to $0.08 \%$ as shown in Fig. 2 (Marique C., 1998). The tin content in TS2 and TS3 and TS6 $(0.048 \leq S \% 0.058)$ here is in consonance with the high yield they returned. Arsenic, equally present in all the five steel samples is much less effective in increasing the steel yield point (Fig. 2).

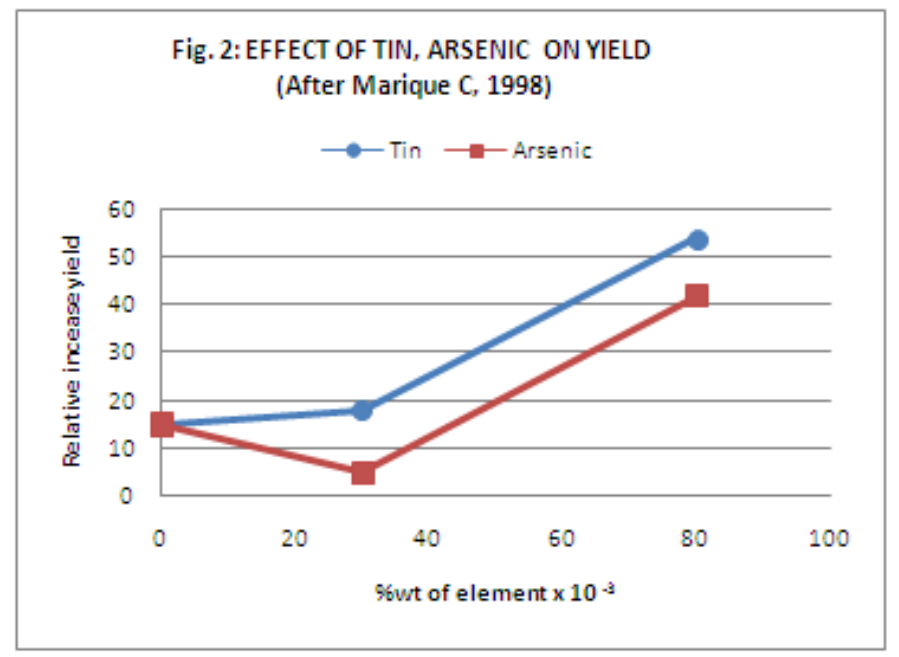

Many of the steels in this study showed a reasonable yield platform. This has been shown earlier to be very important in the effectiveness of steel as concrete reinforcement. While the occurrence of the yield point phenomenon itself is associated with presence of small amounts of interstitial or substitutional impurities since either unlocking of dislocations by a high stress for the case of strong pinning or generation of new dislocations are the reasons for yield-point phenomenon (Satish V, 2009), it is non-the-less true that the existence of these same elements in the form of residual elements gives rise to the elevation of the yield value.

\section{CONCLUSION AND SUGGESTIONS}

The rise of the strength values of steel as a result of the residual element content which is likely to increase with time as more and more scrap is recycled in the absence of industrial processes to remove them will tend to become a more serious problem unless action is taken. The immediate solution to the problem is the use of virgin ore. The ongoing effort to initiate sponge iron projects in some of the county's steel industries is therefore a step in the correct direction whether to be used in combination with scrap as pure tramp element free additions or as outright cleaner steel. 
The fact that the current steel standards are not very clear about the maximum strength values of the steel on the market is worrying. The maximum steel yield needs to be emphasized as much as the minimum is.

\section{REFERENCES}

[1]. Bull D. , Allington C., 2003. L, N and E Grade 500 Reinforcing Steel.

[2]. Callister William D., 2007. Materials Science and Eng. An introduction, $7^{\text {th }}$ Ed, J. Wiley \& Sons, Inc.

[3]. Janke D., Savov L., Weddige H.J., E. Schulz (2000). Scrap-Based Steel Production and Recycling of Steel. Freiberg University of Mining and Technology.

[4]. Marique C., 1998, Tramp elements and steel properties: a progress state of the European project on scrap recycling (C.R.M., Liège, Belgium).

[5]. Meyers, Marc André; Chawla, Krishan Kumar, 2009. Mechanical Behavior of Materials (2 Ed.) Cambridge University Press pg 420-425.

[6]. Murali Fabio D., Roberto R. de Alvillez (2011), Effect of Boron on microstructure and mechanical properties of multiphase steel.

[7]. Paulay, T., Priestley, 1992, Seismic Design of Reinforced Concrete and Masonry Buildings. M.J.N. pp. 114. John Wiley \& Sons, Inc., U.S.A.

[8]. Satish V. Kailas, 2009, Materials Science. Dept. of Mech. Eng., Indian Inst. of Science, Bangalore 560012, India, Ch. 7.

[9]. Senfuka C, Kirabira J.B, Byauhanga J.K, 2012. A Quantitative Evaluation of the Quality of Recycled Steel in Uganda (To be published in the proceedings of the ASME November 9-15, 2012, Houston, Texas, USAIMECE2012-85276 congress).

[10]. Tian Gao and Cristopher D. Moen, The Cold Work Of Forming Effect In Steel Structural Members, Dept. of Civil and Environment Eng., Virginia Tech., e-mails: gaot@vt.edu, cmoen@vt.edu.

[11]. Xu Youlin, 2010, Optimization and Selection of Reinforced Steel Bar Applicable in the Code for Concrete Structures of P. R. China; China Academy of Building Research. 